\title{
ATRIBUTOS FÍSICOS E QUÍMICOS DE UM LATOSSOLO VERMELHO-AMARELO SOB PASTAGENS COM DIFERENTES HISTÓRICOS DE USO ${ }^{(1)}$
}

\author{
Iara Terezinha Pignataro Netto ${ }^{(2)}$, Eiyti Kato $^{(3)} \&$ \\ Wenceslau J. Goedert ${ }^{(4)}$
}

\begin{abstract}
RESUMO
O uso sustentável dos sistemas de pastagens depende, principalmente, de um manejo que possa promover a qualidade do solo. $O$ objetivo deste estudo foi avaliar as alterações nos atributos físicos e químicos do solo sob quatro pastagens, formadas com as espécies Andropogon gayanus, Brachiaria decumbens e Brachiaria brizantha cv. marandu, com diferentes históricos de uso, empregando como referência o Cerrado nativo. $O$ solo foi avaliado pela quantificação dos seguintes atributos: capacidade de troca de cátions, matéria orgânica, densidade do solo, porosidade total e resistência mecânica à penetração. A capacidade de troca de cátions e o teor de matéria orgânica mostraram-se pouco afetados pelo manejo e pelo tempo de uso. A densidade do solo, a porosidade total e a resistência mecânica à penetração foram bastante afetadas, tendo grande influência na redução da qualidade do solo. Quantidade grande de animais, uso de máquinas e implementos, e cobertura deficiente, ocasionada pelo manejo inadequado, foram os principais fatores que promoveram as alterações no solo. $O$ índice de qualidade do solo mostrou uma sequência decrescente, $0,83,0,62,0,51$ e 0,23 , respectivamente, para as áreas sob Andropogon gayanus (AN), Andropogon gayanus (AV), Brachiaria brizantha (BN) e Brachiaria decumbens (BV).
\end{abstract}

Termos de indexação: degradação do solo, resistência mecânica do solo à penetração, densidade do solo, matéria orgânica do solo.

\footnotetext{
(1) Parte da Dissertação de Mestrado da primeira autora apresentada à Universidade de Brasília - UnB. Recebido para publicação em abril de 2008 e aprovado em junho de 2009.

${ }^{(2)}$ Pós-Graduada em Ciências Agrárias da Faculdade de Agronomia e Medicina Veterinária da Universidade de Brasília - UnB. Campus Universitário Darcy Ribeiro, Asa Norte. CEP 70910-970 Brasília (DF). E-mail: ipignataro@yahoo.com.br

(3) Pesquisador Associado, Faculdade de Agronomia e Medicina Veterinária, UnB. E-mail: kato@unb.br

(4) Professor Associado, Faculdade de Agronomia e Medicina Veterinária, UnB. E-mail: goedert@unb.br
} 


\title{
SUMMARY: PHYSICAL AND CHEMICAL PROPERTIES OF AN OXISOL CULTIVATED UNDER PASTURES WITH DISTINCT USE HISTORY
}

\begin{abstract}
The sustainable use of pasture systems depends mainly on a management that promotes soil quality. This study aimed to evaluate changes in the physical and chemical soil properties of four areas under pasture growing the species Andropogon gayanus, Brachiaria decumbens and Brachiaria brizantha, $c v$. marandu, with different usage histories, in comparison to the reference of the natural Cerrado. The soil was evaluated based on the following properties: cation exchange capacity, soil organic matter, bulk density, porosity and soil mechanical penetration resistance. The cation exchange capacity and soil organic matter content were little affected by the management and by usage time. Bulk density, total porosity and soil mechanical penetration resistance were highly affected, with a strong influence on soil quality reduction. The factors high animal load, use of agricultural machines and implements, and deficient groundcover caused by inefficient management were mainly responsible for the soil alterations. The soil quality index showed a decreasing sequence $(0.83,0.62,0.51$ and 0.23 , respectively) for the areas under Andropogon gayanus (AN), Andropogon gayanus (AV), Brachiaria brizantha $(B N)$ and Brachiaria decumbens $(B V)$.
\end{abstract}

Index terms: soil degradation, soil mechanical resistance to penetration, bulk density, soil organic matter.

\section{INTRODUÇÃO}

Um dos grandes desafios nas regiões tropicais é desenvolver sistemas de produção vegetal e animal que possam manter a alta produtividade e a sustentabilidade ambiental. Em geral, nesses agroecossistemas, há predominância de solos muito intemperizados, que necessitam de tratos conservacionistas para manter e melhorar a qualidade dos componentes desse meio. Esta condição dos sistemas agropecuários deve-se, principalmente, ao estado de conservação do solo, que pode mudar com o passar do tempo devido a ocorrências naturais ou de ações geradas pelo homem.

O solo é um importante recurso da natureza com a capacidade de realizar várias funções que exercem influência sobre os constituintes do ambiente. Quando se apresenta em bom estado de conservação e exprime certa qualidade, contribui muito para a sustentabilidade dos sistemas pastoris. Segundo Doran \& Parkin (1994), a qualidade do solo é expressa quando este funciona dentro dos limites de um ecossistema natural, de modo a sustentar a produção biológica, promover a saúde dos animais e das plantas, e manter a qualidade do meio ambiente. Geralmente é determinada por um conjunto de atributos físicos, químicos e biológicos, que representam as diferentes características do solo e que influenciam suas diversas funções. Cada um destes atributos edáficos, por sua vez, pode ou não ter bom desempenho, o que vai influenciar de modo significativo na produção agropecuária.

No ecossistema das pastagens, o solo pode ser considerado como um elemento determinante para o crescimento das gramíneas, pois os seus atributos físicos e químicos atuam diretamente no processo de estabelecimento e desenvolvimento destas plantas. O pisoteio dos animais pode afetar os atributos físicos do solo pela deformação de sua estrutura, promover mudanças na densidade e porosidade, influir na resistência mecânica à penetração e até provocar a compactação do solo. Por outro lado, o conteúdo orgânico pode melhorar a estabilidade dos agregados e ter relevância nos atributos químicos dos solos tropicais. Em geral, solos tropicais possuem baixa fertilidade e a liberação dos nutrientes da matéria orgânica tem grande contribuição como fonte de energia para os organismos e plantas (Cordeiro, 2006). A estrutura física e a fertilidade do solo são fatores importantes envolvidos na formação e no estabelecimento das pastagens. As mudanças evidenciadas nos atributos físicos afetam a movimentação de água, ar, nutrientes e raízes no perfil do solo, bem como nos atributos químicos, sendo a fertilidade do solo indispensável para o desenvolvimento das plantas. Neste contexto, o manejo do solo passa a ser um instrumento essencial para ser usado na busca de atividades agropecuárias sustentáveis (Casalinho \& Martins, 2004).

Santana (2005) comenta sobre a crescente preocupação com a qualidade do ambiente, e vem salientar o anseio por sistemas de cultivo que possam difundir conceitos que visem o desenvolvimento, buscando atender as necessidades atuais e futuras. No Cerrado, há cerca de 50 milhões de hectares de pastagens cultivadas (Sano et al., 1999), e estima-se que $80 \%$ apresentam algum grau de degradação (Aidar \& Kluthcouski, 2003). Esta região, embora com condições físicas muito favoráveis às atividades agropecuárias, possui limitações como baixa disponibilidade de nutrientes e deficiência hídrica em alguns períodos do ano. Os solos cultivados com pastagens, normalmente, são Latossolos distróficos, 
e a falta de elementos essenciais para a manutenção da vegetação provoca um estado de redução no crescimento das plantas, o que contribui para aumentar o processo de degradação (Paciullo et al., 2006).

A qualidade do solo nos sistemas agropastoris concorre com a sustentabilidade das pastagens e, dessa forma, é de suma importância quantificar os seus atributos. O objetivo deste trabalho foi avaliar as alterações nos atributos físicos e químicos do solo sob pastagens, com diferentes históricos de uso, tendo como referência o Cerrado nativo.

\section{MATERIAL E MÉTODOS}

As áreas avaliadas estão localizadas na Fazenda Água Limpa, campo experimental da Universidade de Brasília, no Distrito Federal. A altitude da região varia entre 1.000 e 1.200 m, o clima, segundo a classificação de Köppen, é do tipo Aw (tropical estacional de savana). A precipitação anual média é cerca de $1.550 \mathrm{~mm}$ e a temperatura pode variar entre 18 e $28,5^{\circ} \mathrm{C}$.

O solo nas áreas estudadas é denominado Latossolo Vermelho-Amarelo distrófico típico, A moderado, textura argilosa a muito argilosa e com relevo plano (Embrapa, 1999).

O trabalho foi realizado no período de novembro de 2006 a setembro de 2007, quando foram avaliadas cinco áreas amostrais, sendo quatro com solos sob pastagens e uma sob Cerrado nativo, que serão descritas a seguir: (a) pastagem cultivada com a espécie Andropogon gayanus (AN) é o resultado da rebrota de plantas implantadas em março de 2005, que, pelas dificuldades impostas na época da seca, não apresentaram bom desenvolvimento; com a chegada da chuva, alguns meses depois, ocorreu a recuperação das plantas. Esta área é formada pela associação de árvores e pastagem, e representa, tipicamente, um sistema silvipastoril com componentes arbóreos não cultivados em área de cerrado. O preparo do solo ocorreu de forma irregular, por meio de uma gradagem, realizada nos corredores entre as plantas, com incorporação da vegetação rasteira. Com procedimento semelhante, foram aplicados no solo $1.300 \mathrm{~kg}$ de calcário e $300 \mathrm{~kg}$ de NPK (10-10-10) por hectare. (b) Pastagem cultivada com a espécie Andropogon gayanus (AV) foi implantada há mais ou menos quinze anos e submetida a diversos tipos de tratos culturais, tais como roçagens mecanizadas, construção de terraços de base estreita e aplicação de adubos e corretivos de forma bastante irregular. É uma pastagem antiga com sinais de degradação utilizada para o pastoreio de ovinos, num sistema de rodízio que impõe uma alta lotação animal. (c) Pastagem com a espécie Brachiaria brizantha cv. marandu (BN), implantada no início de 2005, por meio de gradagem, com incorporação da vegetação rasteira e aplicação de cerca de $1.100 \mathrm{~kg}$ de calcário e $300 \mathrm{~kg}$ de NPK (10-10-10) por hectare. Em maio de 2006, foi usada para o pastejo de bovinos e suportou uma alta lotação de animais (3 UA ha-1). (d) Pastagem cultivada com a espécie Brachiaria decumbens (BV), com cerca de quinze anos de uso, e apresenta o pasto em estado avançado de degradação. A implantação da pastagem foi pelo sistema convencional. O solo recebeu algum aporte de nutrientes com certa irregularidade. É um pasto utilizado por bovinos, em tempo integral, com $1 \mathrm{UA} \mathrm{ha}^{-1}$, que representa uma alta lotação animal devido às condições precárias da área. (e) Cerrado nativo $(\mathrm{CN})$ é uma área com solo sob Cerrado stricto sensu, que possui a capacidade de sustentar e manter o equilíbrio no ecossistema desse bioma, usada como referência para os solos cultivados com pastagens. As áreas avaliadas, com cerca de 4 ha cada uma, foram amostradas em duas camadas, de 0-5 e 5-20 cm de profundidade. Para a retirada das amostras de solo, admitiu-se uma linha diagonal imaginária, onde foram marcados três pontos principais e, ao redor de cada um deles, com um raio de $2,5 \mathrm{~m}$, mais quatro pontos, obtendo-se o total de quinze pontos coletados por camada. Os atributos físicos e químicos foram analisados conforme especificações do Manual de Métodos de Análise de Solo (Embrapa, 1997). Os atributos avaliados e os métodos usados foram: densidade do solo (Ds) pelo método do anel volumétrico; porosidade total (Pt) calculada pela fórmula $\mathrm{Pt}=[1-(\mathrm{Ds} / \mathrm{Dp})]^{*} 100$; estabilidade dos agregados determinada por via úmida, calculando-se o diâmetro médio ponderado (DMP) pela equação proposta por Youker \& Mcguiness (1956); capacidade de troca de cátions (CTC) pelos valores da soma de bases $(\mathrm{Ca}+\mathrm{Mg}$ e $\mathrm{K})$ e da acidez potencial $(\mathrm{H}+\mathrm{Al})$, e matéria orgânica do solo pelo método Walkey-Black. A análise granulométrica foi determinada pelo método de Bouyoucos. A resistência mecânica do solo à penetração $(\mathrm{Rp})$ foi medida utilizando-se um penetrômetro marca EIJKELKAMP, com ponteira de $1,0 \mathrm{~cm}$ de diâmetro. As medições foram realizadas em oito pontos, tendo cada um, num raio de $1 \mathrm{~m}$, mais oito medições. A umidade do solo estava em torno de $44 \%$. O delineamento experimental foi inteiramente casualizado em parcelas subdivididas, com três repetições, cada uma sendo a média de cinco subamostras retiradas de cada um dos três pontos da diagonal imaginária. Os dados foram submetidos à análise de variância pelo teste $\mathrm{F}$, ao teste de médias pelo teste Tukey a $5 \%$, e à correlação linear pelo programa SANEST (Zonta \& Machado, 1984). A intensidade das correlações entre os atributos do solo, segundo Gonçalves \& Gonçalves (1985), citado por Guerra \& Liveira (1999), com $\mathrm{p} \leq 0,01$, que apresenta as seguintes faixas: muito forte $(\mathrm{r} \pm 0,91 \mathrm{a} \pm 1,00$, forte $(\mathrm{r} \pm 0,71 \mathrm{a} \pm 0,90)$, média $(\mathrm{r} \pm 0,51 \mathrm{a} \pm 0,70) \mathrm{e}$ fraca $(r \pm 0,31 a \pm 0,50)$.

A avaliação da qualidade do solo foi baseada no modelo comparativo apresentado por Araújo (2004). O solo do Cerrado nativo, um sistema que apresenta condições de estabilidade ecológica, foi considerado com 
qualidade igual a 100\%. O índice de qualidade do solo (IQS) foi determinado por meio dos valores encontrados nos atributos físicos (densidade do solo, porosidade total e resistência mecânica do solo à penetração) e químicos (capacidade de troca catiônica e matéria orgânica do solo). Esta última, apesar de ser um atributo químico, foi considerada, neste modelo, como atributo biológico por ser a base para manutenção dos microorganismos. As três categorias de atributos, físicos, químicos e biológicos, que são representadas no modelo comparativo de qualidade do solo, contribuem de modo igualitário, tendo o mesmo peso cada uma, bem como os indicadores de qualidade do solo, dentro de cada categoria, que têm igual importância relativa. O cálculo da qualidade do solo das áreas de pastagens foi realizado separadamente. Atribuiu-se o valor de $100 \%$ a cada categoria de atributos e este percentual foi dividido na mesma proporção para cada indicador utilizado. A contribuição de cada indicador foi determinada pela soma da percentagem dos desvios de cada um em relação ao valor obtido para o solo do cerrado. Os indicadores evidenciam a influência do uso do solo e, conforme as condições apresentadas, podem contribuir de modo benéfico ou não para a qualidade do solo. O exemplo citado por Araújo et al. (2007) mostra que ocorre uma redução de 50\% na qualidade da Ds, quando esta apresenta valor igual a $1,2 \mathrm{~kg} \mathrm{dm}^{-3}$ na área a ser avaliada e $0,8 \mathrm{~kg} \mathrm{dm}^{-3}$ na área referência. Os valores individuais dos indicadores foram agregados gerando um valor percentual para cada atributo (físico, químico e biológico) da área estudada. Esses valores foram colocados em um diagrama com três eixos, um para cada atributo, para ser calculado o IQS. Então, a área geográfica do triângulo resultante de cada gleba de pastagem foi comparada com a área resultante do Cerrado nativo.

\section{RESULTADOS E DISCUSSÃO}

Os solos sob pastagens, com exceção do solo sob braquiária $(\mathrm{BN})$, que possui textura média na camada de $0-5 \mathrm{~cm}$ e argilosa, de $5-20 \mathrm{~cm}$, possuem textura argilosa e muito argilosa nestas camadas. O Cerrado nativo mostrou ser muito argiloso nas duas camadas estudadas. Nos atributos físicos analisados, apresentados no quadro 1, foram observadas diferenças significativas entre as áreas, indicando que os solos foram afetados pelo manejo e tempo de uso.

A densidade do solo e a porosidade total foram mais afetadas nas áreas com andropogon velho (AV) e braquiária nova $(\mathrm{BN})$, na camada de $0-5 \mathrm{~cm}$ de profundidade. A Ds, nestas duas glebas, mostrou diferença significativa nas profundidades de cada uma das áreas, possivelmente a principal causa foi o pisoteio de muitos animais em pastejo. De acordo com Kondo \& Dias Junior (1999), o efeito do pisoteio animal é mais pronunciado nos primeiros centímetros do solo, geralmente de $0-3 \mathrm{~cm}$ de profundidade. Por outro lado, na camada de 5-20 cm, a área com andropogon novo (AN) foi similar à área de referência, sugerindo que a menor perturbação, devido à ausência de animais,

\section{Quadro 1. Atributos físicos do solo sob pastagens e Cerrado nativo, em duas camadas}

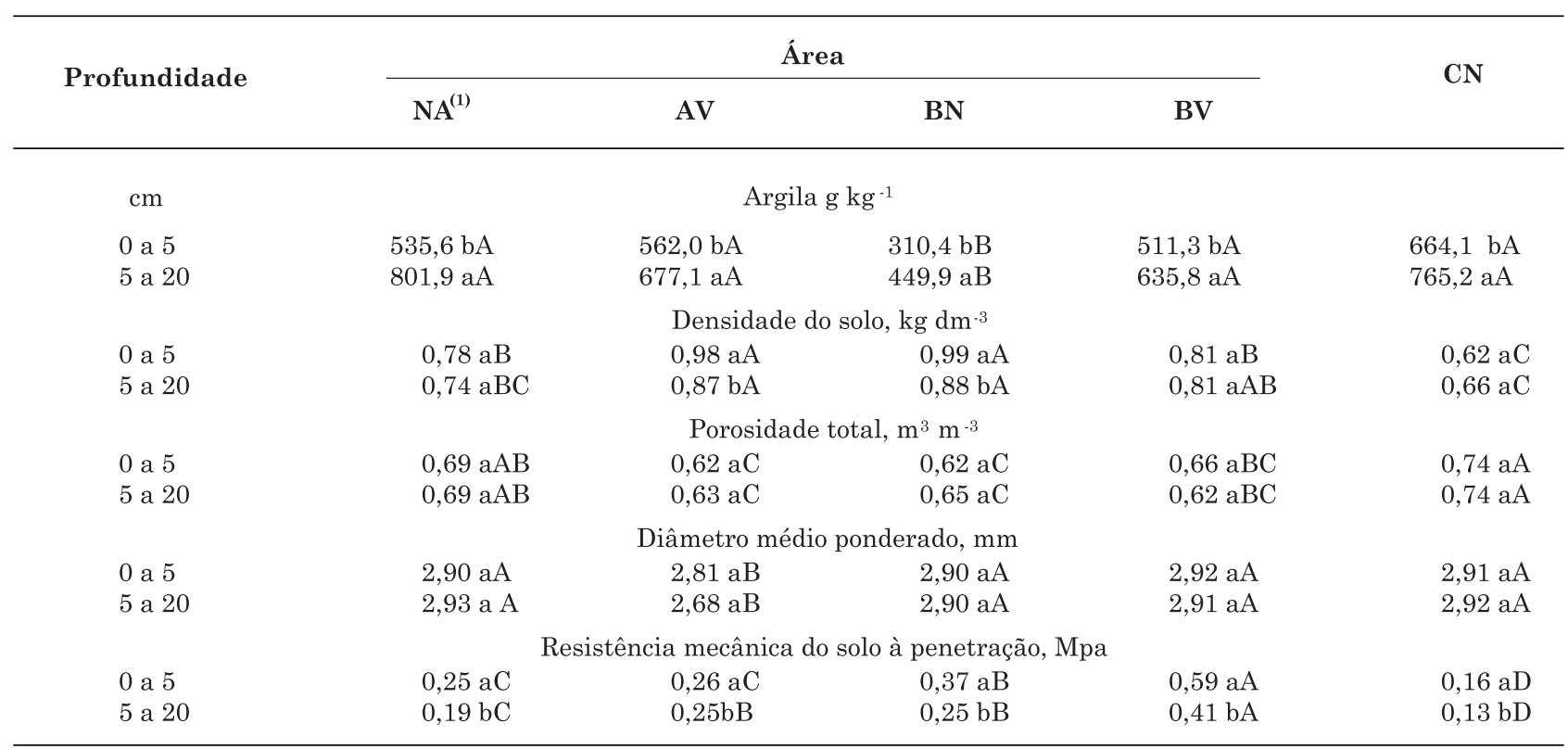

(1) AN, Andropogon gayanus; AV, Andropogon gayanus; BN, Brachiaria brizantha; BV, Brachiaria decumbens; CN, Cerrado nativo. Letras maiúsculas comparam áreas entre colunas e letras minúsculas comparam camadas entre linhas nos tratamentos. Médias seguidas de mesma letra não diferem entre si pelo teste de Tukey a $5 \%$. 
propiciou melhor condição deste atributo. Os maiores valores de Ds observados nas pastagens são similares aos encontrados por Araújo et al. (2007) e Neves et al. (2007), em pastagem cultivada por um período semelhante. Embora a densidade nos solos analisados seja maior do que no Cerrado nativo, nenhuma das áreas apresentou um valor limitante, a partir do qual ocorrem restrições ao desenvolvimento radicular. Segundo Bowem (1981), citado por Camargo \& Alleoni (1997), este valor é cerca de $1,55 \mathrm{~g} \mathrm{~cm}^{-3}$ para solos médios e argilosos. Os valores de porosidade total não diferem em profundidade e os mais baixos são similares aos encontrados por Marchão et al. (2007), em pastagem contínua, na região do Cerrado. A maior porosidade observada entre as pastagens no solo AN possivelmente foi bastante influenciada pelas raízes em decomposição das gramíneas, dos arbustos e das árvores. Em estudos com sistemas agroflorestais, Carvalho et al. (2004) relataram que a contribuição das árvores foi importante no melhor estado daquele ambiente, o que reforça a boa condição encontrada no solo sob AN, com plantas arbóreas remanescentes do cerrado. Esta propriedade pode variar conforme a textura, a profundidade, o teor de matéria orgânica, o preparo do solo e o sistema de cultivo (Fageria \& Stone, 2006).

A estabilidade dos agregados, representada pelo DMP, em quase todas as áreas foi similar à do Cerrado nativo. A diferença ficou por conta do solo sob AV, com o menor DMP. A redução no tamanho dos agregados pode ter ocorrido devido à maior pressão recebida por este solo, e pela influência negativa da pouca cobertura e teor de matéria orgânica, que foi verificado pela tendência de redução nos valores deste solo, embora estatisticamente similar aos demais. A cobertura e o fornecimento contínuo de material orgânico atuam como agente de formação e estabilização da estrutura (Martins et al., 2002).

Na resistência mecânica do solo à penetração $(\mathrm{Rp})$, ocorreram diferenças altamente significativas entre as áreas e entre as camadas de cada área. Os maiores valores foram encontrados na camada de $0-5 \mathrm{~cm}$, evidenciando o tipo de manejo, a presença de muitos animais e um longo tempo de uso. A área com BV relata a presença de animais acima de sua capacidade de oferta por muitos anos. Isso pode ter contribuído para a redução da cobertura do solo e intensificado os efeitos causados pela chuva e, principalmente, pelos animais em pastejo, resultando na maior resistência do solo também na segunda camada. $\mathrm{O}$ aumento da resistência mecânica na camada superficial da área com $\mathrm{BN}$ pode ter sido influenciado pela textura média do solo que, naturalmente mais frágil em condições tropicais, foi afetado com maior intensidade pelo processo de implantação e alta lotação de animais em pastejo. Segundo Imhoff et al. (2000), a proporção e o tipo das mudanças ocorridas nas características do solo, causadas pelo pisoteio animal, dependem da intensidade do pisoteio, da umidade e do tipo de solo. Os menores impedimentos encontrados nas áreas com $\mathrm{AN}$ e AV podem ter causas distintas. A primeira, provavelmente é devido à pressão das máquinas na implantação da pastagem e pela movimentação do solo realizada por raízes maiores das árvores. No processo de preparo do solo ocorre a influência direta dos implementos agrícolas nas propriedades físicoquímicas (Fageria \& Stone, 2006). A segunda, pelo manejo imposto, com alta lotação e longo tempo de uso.

Os atributos químicos dos solos estudados, que estão apresentados no quadro 2 , demonstram que a capacidade de troca de cátions (CTC) apresentou diferença entre as áreas e as camadas de cada área. A matéria orgânica foi similar entre todos os solos e distinta na profundidade de cada área.

Estatisticamente, a CTC do solo sob AN, mais elevada, distinguiu-se dos solos sob AV, BN e BV que foram semelhantes à do Cerrado nativo. A CTC do solo sob AN, possivelmente, teve grande contribuição dos resíduos orgânicos produzidos pela gramínea e pelos arbustos e árvores daquela área. Os maiores valores foram encontrados na camada de $0-5 \mathrm{~cm}$, onde

Quadro 2. Capacidade de troca de cátions e matéria orgânica do solo sob pastagens e Cerrado nativo, em duas camadas

\begin{tabular}{|c|c|c|c|c|c|}
\hline \multirow{2}{*}{ Profundidade } & \multicolumn{4}{|c|}{ Área } & \multirow{2}{*}{$\mathrm{CN}$} \\
\hline & $\mathrm{AN}^{(1)}$ & AV & BN & BV & \\
\hline $\mathrm{cm}$ & \multicolumn{4}{|c|}{ CTC, $\mathrm{cmol}_{c} \mathrm{dm}^{-3}$} & \\
\hline 0 a 5 & 10,86 aA & $8,18 \mathrm{aB}$ & $8,44 \mathrm{aB}$ & $9,15 \mathrm{aB}$ & $9,00 \mathrm{aB}$ \\
\hline 5 a 20 & $8,26 \mathrm{bA}$ & $7,14 \mathrm{bAB}$ & $7,36 \mathrm{bAB}$ & $8,17 \mathrm{bA}$ & $6,55 \mathrm{bB}$ \\
\hline \multicolumn{6}{|c|}{ Matéria orgânica $\mathrm{g} \mathrm{kg}^{-1}$} \\
\hline 0 a 5 & $61,1 \mathrm{aA}$ & 54,7 aA & $60,4 \mathrm{aA}$ & $58,4 \mathrm{aA}$ & $57,1 \mathrm{aA}$ \\
\hline 5 a 20 & $48,6 \mathrm{bA}$ & $49,4 \mathrm{bA}$ & $54,6 \mathrm{bA}$ & $52,6 \mathrm{bA}$ & 48,8 bA \\
\hline
\end{tabular}

${ }^{(1)} \mathrm{AN}$, Andropogon gayanus; AV, Andropogon gayanus; BN, Brachiaria brizantha; BV, brachiaria decumbens; CN, Cerrado nativo. Letras maiúsculas comparam áreas entre colunas e letras minúsculas comparam camadas entre linhas nos tratamentos. Médias seguidas de mesma letra não diferem entre si pelo teste de Tukey a $5 \%$. 
ocorre a contribuição mais expressiva da matéria orgânica. Nas regiões tropicais, a matéria orgânica pode representar uma grande parte da CTC total dos solos (Bayer \& Mielniczuk, 1999). Nos Latossolos distróficos, a fração mineral é pobre e a maior parte de suas cargas é acrescentada ao solo pela matéria orgânica, que se apresenta em maior quantidade na superfície e diminui em profundidade, o que pode explicar a ocorrência da CTC mais baixa, em todas as áreas, na camada de 5-20 cm.

Em relação à matéria orgânica, observou-se que, estatisticamente, ocorreram diferenças entre as camadas das áreas, ocorrendo os maiores valores na camada de $0-5 \mathrm{~cm}$. Justifica-se tal diferença entre as camadas pela presença de grande quantidade de raízes das gramíneas que se acumulam próximo da superfície. Cerca de 40 a $50 \%$ do carbono do solo pode ser armazenado até $30 \mathrm{~cm}$ (Salton et al., 2005). A semelhança no teor de matéria orgânica entre as áreas de pastagens e o Cerrado nativo é devida ao comportamento das gramíneas que são excelentes incorporadoras de matéria orgânica no solo. Braz et al. (2004), analisando o carbono orgânico do solo em pastagens de braquiária, com 5 e 18 anos de uso contínuo, encontrou o conteúdo de matéria orgânica maior do que na mata nativa.

$\mathrm{Na}$ análise da relação entre os atributos dos solos estudados foi observado uma correlação altamente significativa e direta entre $\operatorname{Ds} x \operatorname{Rp}\left(0,38^{* *}\right)$ e MOS x CTC $\left(0,71^{* *}\right)$, assim como, significativa e indireta entre Ds x DMP $\left(-0,36^{*}\right)$ e argila x MOS $\left(-0,45^{*}\right)$. A correlação fraca e altamente significativa que ocorreu entre a densidade e a resistência mecânica do solo à penetração indica que esta última pode ter sido influenciada pela maior densidade encontrada nas áreas com braquiária. A correlação forte e altamente significativa entre a matéria orgânica e a capacidade de troca de cátions evidenciou a contribuição expressiva que a MOS fornece à CTC destas áreas de pastagens, o que corrobora os trabalhos de Silva \& Resck (1997), Salton et al. (2005) e Fialho et al. (2006). A correlação média e negativa da densidade do solo com a argila pode ser devida ao menor teor de argila encontrado na área com braquiária nova, e consequentemente, maior quantidade de areia, que exerceu influência na alta densidade desta área. Segundo Vieira (1988), os solos com maior percentual de areia possuem densidade mais elevada do que aqueles com mais argila. A correlação fraca e negativa entre a densidade do solo e o diâmetro médio ponderado demonstrou que a menor agregação encontrada na área com AV teve uma pequena contribuição no aumento da densidade desta área, porém não influiu diretamente na resistência mecânica do solo. A correlação fraca e negativa entre a argila e a matéria orgânica sugere a diferença no teor dos dois componentes em relação à profundidade do solo. As áreas avaliadas apresentaram na camada superficial menor teor de argila e maior quantidade de matéria orgânica e, na camada de 5-20 cm, aumentou o teor de argila e reduziu o de matéria orgânica. Entretanto, na área com $\mathrm{BN}$, tendo em vista a homogeneização do solo pela grade na implantação da pastagem, esses dois componentes mostram pouca diferença na influência que exerceram, confirmando assim a baixa correlação apresentada.

A qualidade dos solos (Qs) sob pastagens, apresentada na figura 1 , demonstra que, em relação ao Cerrado nativo, os atributos químicos e orgânicos foram pouco alterados ao contrário dos atributos físicos. Resultados similares foram encontrados por Araújo et al. (2007) em solos sob pastagem cultivada e nativa.

$\mathrm{O}$ diagrama 1a mostra o solo sob $\mathrm{AN}$ com a maior qualidade entre as áreas de pastagens. O IQS de 0,83 evidencia o bom estado de conservação do solo. No diagrama 1b, a área com AV mostra um IQS de 0,62. Observa-se que houve uma redução na qualidade deste solo em relação à área anterior. No diagrama 1c, pode-se verificar que o solo sob $\mathrm{BN}$ apresentou modificações acentuadas nos seus atributos físicos, provocando um IQS de 0,51, cerca de $50 \%$ inferior ao IQS do Cerrado nativo. No diagrama 1d, o solo com BV mostrou o menor IQS entre todas as áreas, 0,23, sugerindo que os atributos físicos foram bastante alterados pelo tempo e pelas condições de uso.

Após estudar o comportamento do solo das áreas com pastagens por meio dos diversos atributos, podese observar que os efeitos negativos para a Qs são mais pronunciados na camada de 0 a $5 \mathrm{~cm}$, e, independente do manejo utilizado, os atributos físicos foram os mais afetados, confirmando sua importância na relação inversa entre a intensidade de uso e a qualidade dos solos.

Entre as áreas com pastagens ocorreu dissimilaridade, e os índices de qualidade mais elevados estão representados nos solos das duas áreas com andropogon. A gleba com AN demonstrou a melhor conservação do solo, e com BV a pior, quando comparados ao Cerrado nativo. A influência negativa dos atributos físicos foi mais pronunciada na área com $\mathrm{BV}$, seguida por BN, AV e AN. Entre as áreas com braquiárias, encontrou-se uma diferença de $55 \%$ na qualidade do solo, e entre as com andropogon, cerca de $25 \%$, sugerindo que, nas áreas de pastagens, a intensidade e o tempo de uso influenciaram na redução da Qs, afetando a estrutura do solo, impondo certa impedância mecânica, que pode ter reflexos na infiltração da água e no aumento da erosão superficial, bem como na movimentação das raízes pelo perfil do solo.

Entre os atributos avaliados foi possível constatar que a resistência mecânica à penetração melhor refletiu as diferenças no estado de conservação do solo entre as áreas. Por ser uma propriedade de boa aplicabilidade em campo e que mostra com certa facilidade as situações de impedimento no solo, pode ser usada como um bom indicador de sustentabilidade das pastagens. 
MODELO COMPARATIVO E ÍNDICE DE QUALIDADE DO SOLO (IQS)

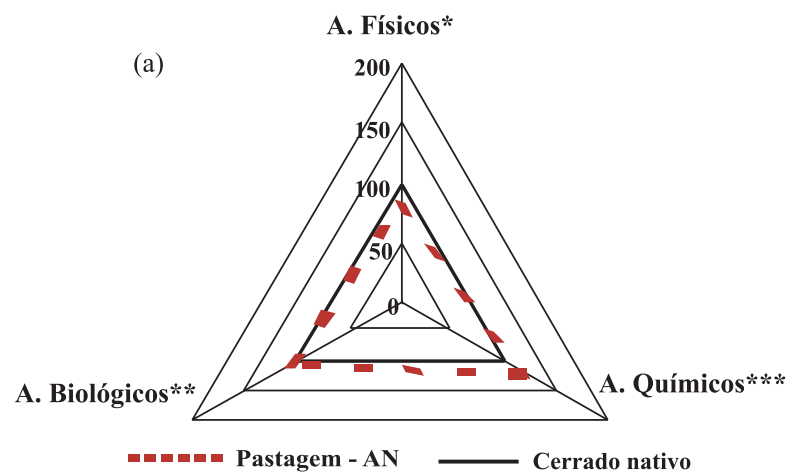

(b)

A. Físicos

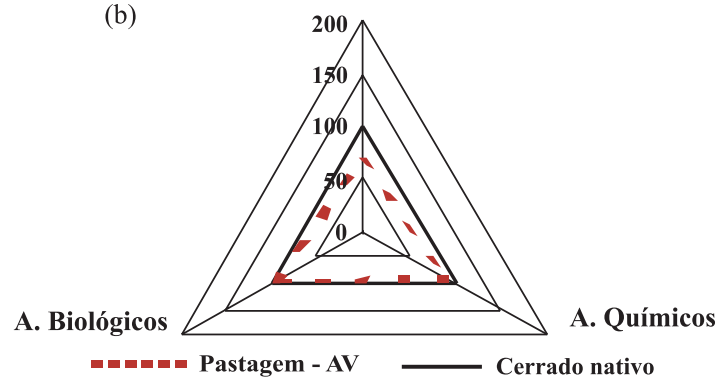

A. Físicos

(c)

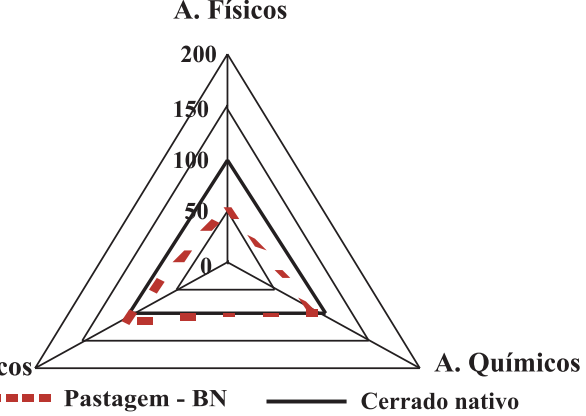

A. Biológicos

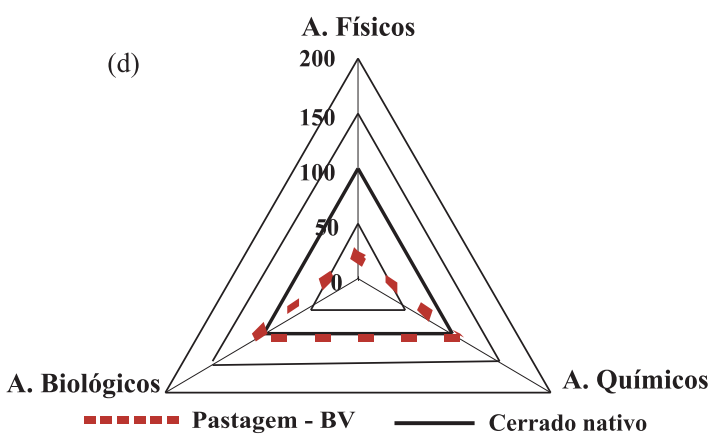

Figura 1. Diagramas comparativos da qualidade do solo, com diferentes tempos de uso, entre as áreas de pastagens e o Cerrado nativo. *: densidade do solo, porosidade e resistência do solo à penetração; **: matéria orgânica; ***: capacidade de troca de cátions.

O sistema de manejo das áreas tem grande influência nos atributos físicos do solo, especialmente na camada superficial, onde ocorre a maior pressão do pisoteio animal. Com o tempo, a degradação mecânica do solo leva à compactação, que é um dos fatores responsáveis pela perda de produtividade em áreas de pastagens.

\section{CONCLUSÕES}

1. Em relação ao Cerrado nativo, todas as áreas com pastagens apresentam reduções na qualidade do solo. Observa-se que, mesmo na área com a menor atividade (AN), a interferência produzida pelo preparo do solo causa algumas alterações nos atributos físicos, bem como o uso mais intenso e prolongado nas demais áreas provoca efeitos negativos mais acentuados.

2. As pastagens apresentam diferenças na qualidade do solo conforme o manejo imposto em cada área. $\mathrm{O}$ uso impróprio, principalmente, com a presença de muitos animais em pastejo, resultou na maior redução de qualidade nos solos com braquiárias. Contudo, os tratos culturais realizados na pastagem mais antiga, com andropogon, promoveram melhorias no solo. E, notadamente, na área mais nova (AN), a significativa contribuição da matéria orgânica do sistema silvipastoril, aliada à não utilização pelos animais, proporcionou melhor estrutura do solo.

3. Os atributos físicos que mais influenciaram na redução da qualidade do solo foram densidade do solo, porosidade total e resistência mecânica do solo, sendo este último o que melhor refletiu os efeitos do sistema de manejo das pastagens.

4. Os atributos químicos foram pouco afetados pelo uso do solo, possivelmente pela expressiva contribuição da matéria orgânica produzida pelas gramíneas.

\section{LITERATURA CITADA}

AIDAR, H. \& KLUTHCOUSKI, J. Evolução das atividades lavoureira e pecuária nos cerrados. In: AIDAR, H.; STONE, L.F. \& KLUTHCOUSKI, J., eds. Integração lavourapecuária. Santo Antonio de Goiás, Embrapa Feijão e Arroz, 2003. p.23-58.

ARAÚJO, R. Avaliação da qualidade do solo em diferentes usos. Brasília, Universidade de Brasília, 2004. 77p. (Tese de Mestrado)

ARAÚJO, R.; GOEDERT, W.J. \& LACERDA, M.P.C. Qualidade de um solo sob diferentes usos e sob cerrado nativo. $R$. Bras. Ci. Solo, 31:1099-1108, 2007.

BAYER, C. \& MIELNICZUK, J. Dinâmica e função da matéria. In: SANTOS, G.A. \& CAMARGO, F.A.O., eds. Fundamentos da matéria orgânica do solo: Ecossistemas tropicais e subtropicais. Porto Alegre, Genesis, 1999. p.926. 
BRAZ, S.P.; URQUIAGA, S.; ALVES, B.J.R. \& BODDEY, R.M. Degradação de pastagens, matéria orgânica do solo e a recuperação do potencial produtivo em sistemas de baixo "input" tecnológico na região dos Cerrados. Brasília, Embrapa, 2004. (Circular Técnica, 9)

CAMARGO, O.A. \& ALLEONI, L.R.F. Compactação do solo e o desenvolvimento das plantas. Piracicaba, Escola Superior de Agricultura Luiz de Queiroz, 1997. 132p.

CARVALHO, R.; GOEDERT, W.J. \& ARMANDO, M.S. Atributos físicos da qualidade um solo sob sistema agroflorestal. Pesq. Agropec. Bras., 39:1153-1155, 2004.

CASALINHO, H.D. \& MARTINS, S.R. Qualidade do solo como indicador de sustentabilidade em agroecossistemas: avaliações integrando os conhecimentos acadêmicos e não-acadêmicos. In: CANUTO, J.C. \& COSTABEBER, J.A. Agroecologia: Conquistando a soberania alimentar. Porto Alegre, Emater/RS-Ascar; Pelotas, Embrapa Clima Temperado, 2004. p.212-225.

CORDEIRO, F.C. Atributos edáficos em área de pastagem plantada em relevo movimentado no noroeste do Estado do Rio de Janeiro. Seropédica, Universidade Federal Rural do Rio de Janeiro, 2006. 89p. (Tese de Mestrado)

DORAN, J.W. \& PARKIN, T.B. Defining and assessing soil quality. In: DORAN, J.W. \& COLEMAN, D.C.; BEZDICEK, D.F. \& STEWART, B.A. Defining soil quality for sustainable environment. Madison, Soil Science Society of America Proceedings, 1994. p.3-21. (SSSA Special Publication, 35)

EMPRESA BRASILEIRA DE PESQUISA AGROPECUÁRIA EMBRAPA. Centro Nacional de pesquisa de solos. Sistema brasileiro de classificação de solos. Rio de Janeiro, 1999. $412 \mathrm{p}$

EMPRESA BRASILEIRA DE PESQUISA AGROPECUÁRIA EMBRAPA. Centro Nacional de pesquisa de solos. Manual de métodos de análise de solo. 2.ed. Rio de Janeiro, 1997. $212 p$.

FAGERIA, N.K. \& STONE, L.F. Qualidade do solo e meio ambiente. Santo Antônio de Goiás, Embrapa Arroz e Feijão, 2006. (Documento / Embrapa Arroz e Feijão, 197)

FIALHO, J.S.; GOMES, V.F.F.; OLIVEIRA, T.S. \& SILVA JUNIOR, J.M.T. Indicadores da qualidade do solo em áreas sob vegetação natural e cultivo de bananeiras na Chapada do Apodi-CE. R. Ci. Agron., 37:250-257, 2006.

GUERRA, N.B. \& LIVEIRA, A.V.S. Correlação entre o perfil sensorial e determinações físicas e químicas do abacaxi cv. Pérola. R. Bras. Frutic., 21:32-35, 1999.

IMHOFF, S.; SILVA, A.P. \& TORMENA, C.A. Aplicações da curva de resistência no controle da qualidade física de um solo sob pastagem. Pesq. Agropec. Bras., 35:1493-1500, 2000.
KONDO, M.K. \& DIAS JUNIOR, M.S. Compressibilidade de três Latossolos em função da umidade e uso. R. Bras. Ci. Solo, 23:211-218, 1999.

MARCHÃO, R.L.; BALBINO, L.C.; SILVA, E.M.; SANTOS JUNIOR, J.D.G.; SÁ, M.A.C.; VILELA, L. \& BECQUER, T. Qualidade física de um Latossolo Vermelho sob sistemas de integração lavoura-pecuária no Cerrado. Pesq. Agropec. Bras., 42:873-882, 2007.

MARTINS, S.G.; SILVA, M.L.N.; CURI, N. \& FERREIRA, M.M. Avaliação dos atributos físicos de um Latossolo Vermelho distroférrico sob diferentes povoamentos florestais. Cerne, 18:32-41, 2002

NEVES, C.M.N.; SILVA, M.L.N.; CURI, N.; CARDOSO, E.L.; MACEDO, R.L.G.; FERREIRA, M.M. \& SOUZA, F.S. Atributos indicadores da qualidade do solo em Sistemas Agrossilvipastoril no Noroeste do Estado de Minas Gerais. Sci. Flor., 74:45-53, 2007.

PACIULLO, D.S.C.; AROEIRA, L.J.M. \& PIRES, M.F.A. Sistemas Silvopastoris para a produção de leite. In: PEDREIRA, C.G.S.; MOURA, J.C.; SILVA, S.C. \& FARIA, V.P., eds. AS PASTAGENS E O MEIO AMBIENTE SIMPÓSIO SOBRE MANEJO DA PASTAGEM. 23., Piracicaba, 2006. Anais. Piracicaba, FEALQ, 2006. p.327352.

SALTON, J.C.; MIELNICZUK, J.; BAYER, C.; FABRICIO, A.C.; MACEDO, M.C.M.; BROCH, D.L.; BOENI, M. \& CONCEIÇÃO, P.C. Matéria orgânica do solo na interação lavoura-pecuária em Mato Grosso do Sul. Dourados, Embrapa Agropecuária Oeste, 2005. 58p. (Boletim de Pesquisa e Desenvolvimento, 29)

SANO, E.E.; BARCELLOS, A.O. \& BEZERRA, H.S. Área e distribuição espacial de pastagens cultivadas no Cerrado Brasileiro. Planaltina, Embrapa Cerrados, 1999. 21p. (Embrapa Cerrados, Boletim de Pesquisa, 3)

SANTANA, D.P. A agricultura e o desafio do desenvolvimento sustentável. Sete Lagoas, 2005. (Comunicado Técnico, 132)

SILVA, J.E. \& RESCK, D.V.S. Matéria orgânica do solo. In: VARGAS, M.A.T. \& HUNGRIA, M. Biologia dos solos do cerrados. Planaltina, Embrapa, 1997. p.465-524.

VIEIRA, L.S. Manual da ciência do solo: Com ênfase aos solos tropicais. 2.ed. São Paulo, Agronômica Ceres, 1988. 464p.

ZONTA, E.P. \& MACHADO, A.A. SANEST - Sistema de Análise Estatística. Campinas, Instituto Agronômico de Campinas, 1984.

YOUKER, R.E. \& MCGUINESS, J.L. A short method of obtaining mean weight-diameter values of aggregates of soil. Soil Sci., 83:291-294, 1956. 